\title{
A Business Failure Index Using Rank Transformation
}

\author{
Marialuisa Restaino ${ }^{1} \&$ Marco Bisogno $^{2}$ \\ ${ }^{1}$ Department of Economics and Statistics, University of Salerno, Italy \\ ${ }^{2}$ Department of Management \& Innovation Systems, University of Salerno, Italy \\ Correspondence: Marialuisa Restaino, Department of Economics and Statistics, University of Salerno, Via \\ Giovanni Paolo II, 132, 84084, Fisciano (SA), Italy. Tel: 039-089-962-645. E-mail: mlrestaino@ unisa.it
}

Received: November 6, 2018

Accepted: November 26, 2018 Online Published: December 15, 2018

doi:10.5539/ijef.v11n1p56

URL: https://doi.org/10.5539/ijef.v11n1p56

\begin{abstract}
The global financial crisis entails a renewed attention from financial institutions, academics, and practitioners to corporate distress analysis and its forecasting. This study aims to propose a model for predicting default risk based on a business failure index using rank transformation. The procedure suggested is able to capture firms' financial difficulties and forecast bankruptcy through the construction of a failure index based on some relevant financial ratios. By means of the estimation of failure probability, it allows to classify and predict business distress in time to take mitigating action. This procedure is evaluated by some accuracy measures on a sample of Italian manufacturing firms, and is found to be a suitable instrument for preventing financial distress.
\end{abstract}

Keywords: bankruptcy prediction, index approach, rank transformation

\section{Introduction and Background}

Forecasting business failure is one of the most significant threats to all parties involved into firms' management since it produces substantial losses to companies' creditors, investors, financial institutions, stakeholders, employees, and customers, and inevitably influences the society and the aggregate economy.

Moreover, the global financial crisis, begun in the second half of 2008, has caused a significant increase in the number of companies in danger of failure. Therefore, predicting the bankruptcy of firms has become increasingly important and worthwhile to analyze.

Qualified forecasting models for default risk, including discriminant analysis (Beaver, 1966; Altman, 1968), logit and probit regression (Ohlson, 1980; Zmijewski, 1984; Lennox, 1999; Charitou et al., 2004; Jones \& Hensher, 2004), classification trees and artificial neural network (Frydman et al., 1985; Wilson \& Sharda, 1994; Perez, 2006; Gepp et al., 2010), survival analysis (Lane et al., 1986; Luoma \& Laitinen, 1991; Shumway, 2001; Gepp \& Kumar, 2008; du Jardin \& Severin, 2011), have been intensively developed and extensively applied in real-world cases. Besides, they should be useful instruments to foresee financial difficulties or firms' distress.

Before adopting these approaches to forecast companies collapse, it is important to take into account that corporate failure is not a sudden phenomenon, but it is a dynamic process which evolves over a considerable period (Altman, 1968; Argenti, 1976; Korol, 2013). Therefore, it becomes relevant to implement models able to detect early warning signals and predict firms' distress as early as possible, so that managers could have enough time for preparing and bringing about some effective actions to restore firms' finances.

All the models mentioned above used accounting-based financial ratios that do not meet the theoretical assumptions (Deakin, 1972; Frecka \& Hopwood, 1983; Lee, 1985), with the consequence that the researchers have to deal with several problems: the non-normal distributions of the most of ratios, the ratio "blow-up" phenomenon, the identification and treatment of outliers, the difficulty in interpreting and using negative ratios within a distribution (Lev \& Sunder, 1979; Kane \& Meade, 1998). In order to overcome these problems, some attempts, such as trimming the sample ratios, eliminating negative observations, and using different transformations (e.g. logarithms, square roots, ranks), have been done (Frecka \& Hopwood, 1983; So, 1987; So, 1994; Kane \& Meade, 1998). Furthermore, some authors (Kane et al., 1998; Kane \& Meade, 1998) have suggested an approach based on a non-parametric transformation, that is related to the notion of ranks. Rank transformation is achieved by replacing each observation with its respective rank within a sample. Simply stated, the value of each variable of the samples is replaced by its rank from one for the smallest to rank $n$ (equal to the 
number of firms) for the largest.

Such a technique has been examined for its statistical properties by Iman and Conover (1979) and by Conover and Iman (1980) when it is used in regression analysis and discriminant analysis. These authors proved that when rank transformations are applied, the results are robust and the procedure, compared to standard methods, is much less sensitive to outliers and/or non-normal distributions.

Moreover, rank transformations have been used successfully in many applications, among the other predicting corporate bond ratings (Perry et al., 1985; Perry \& Cronan, 1986; Skomp et al., 1986), assessing corporate strategic risk (Collins \& Ruefli, 1992), forecasting the likelihood of corporate failure (Perry et al., 1986; Kane et al., 1996). Liao and Mehdian (2016) used the rank transformations for estimating an aggregate bankruptcy index based on five financial ratios, in order to predict the propensity of financial failure and corporate bankruptcy. They ranked individual financial ratios into deciles with the least distressed firms taking the value of 10 , and the most distressed taking the value of 1 . They assessed the robustness of the index, by comparing the predictive accuracy of their approach and that of the Altman's Z-score.

This methodology offers a good alternative method when it is involved in assessing and predicting the likelihood of corporate failure since there are several advantages. Firstly, it avoids the restrictive normality assumption. Secondly, the multicollinearity among the financial ratios can be avoided because this approach is non-parametric. Finally, functional form is not imposed on data set.

Moreover, the rank transformation has some important distributional properties, that should improve the usefulness and the robustness of failure prediction models. Among these properties, it is worth recalling that ranked variables are uniformly distributed, with zero skewness and, in many cases, improved kurtosis as compared to the untransformed variable. Then, scaled ranks are also naturally bounded between 0 and 1 .

Thanks to the advantages and the distributional properties mentioned, rank transformations appear capable of reducing the influence of outliers and non-normal distributions while preserving general form. Moreover, the result is a robust procedure that, compared to standard methods, is much less sensitive to outliers and/or non-normal distributions. Then, the use of rank data has been shown to improve fit and be less biased than linear models with untransformed data (Lertwachara \& Boonchoo, 2006).

Therefore, their usage is suggested to improve robust failure prediction models, such as logistic regression, without the need for other conditioning methods, such as truncation and winsorization, that necessitate the loss of data and/or limitation of the relevant range (Kane et al., 1998).

Because of all this, our study aims to apply rank transformations to financial ratios for estimating a business failure index that can be used as a measure of firms' global performance in order to improve the predictive usefulness of standard failure prediction models. In particular, the aggregate index computed takes into account a larger number of ratios compared with those considered in Liao and Mehdian (2016), so that it is possible to capture which ratios are more likely to influence the risk of failure. Moreover, for comparison and assessment of the robustness of our approach, we estimated the distress probability by logit regression, using the same set of financial ratios to compare the predictive accuracy of two approaches.

The remainder of the article is structured as follows. Section 2 will illustrate the research methodology, introducing the data used and showing the proposed approach, while Section 3 will present and discuss the main results. The last section will conclude, also drawing the limitations of the study and further developments of the research.

\section{Research Methodology}

\subsection{The Data Source and Explanatory Variables}

In this study, the data refers to a sample of Italian manufacturing firms and the information is collected from the Orbis database, managed by Bureau van Dijk, for the period 2007-2015. The Italian context is chosen as a representative case of the European civil law-based countries, whose legislation is inspired by the ancient Roman law. Indeed, Italy can be considered as one of the founding fathers of the modern legislation of the continental European countries (Bisogno \& De Luca, 2014).

Since business failure can be defined in many different ways and there is not a unique and widely accepted definition (Crutzen \& Van Caillie, 2007), this study focuses on the bankruptcy proceedings as defined by the data provider: "bankruptcy is a legally declared inability of a company to pay its creditors. The company is in the process of bankruptcy. The assets are being sold in order to repay the creditors. At the end, the company will be dissolved and will no longer exist." 
When collecting the data, companies with full information for all years before the occurrence of the bankruptcy have been considered. Secondly, a sufficient number of comparable companies of similar size in the same industry for comparison of the bankrupt and non-bankrupt cases should be available.

Since a significant difference between the number of bankrupt and non-bankrupt cases could lead to a severely imbalanced classification problem and a degradation in the final prediction performance, we collect the same number of bankrupt and non-bankrupt units by a stratified random sampling with stratification on default indicator (Altman, 1968; Platt \& Platt, 2002). The firms within each group are selected at random.

The independent variables are calculated using data from the financial statements of firms included in the sample. Since no single theory could serve as a guide to select explanatory variables to predict bankruptcy, this study only considers the set of financial ratios from the list available from the data provider, checking that they have some effects on business failure and have been used in studies on bankruptcy prediction. Moreover, we excluded those ratios for which the information needed to calculate them is missing. Table 1 shows the variables with the area they belong to and the formula used to compute them.

Table 1. Financial ratios used in the study

\begin{tabular}{|c|c|c|}
\hline Area & Ratio & Formula \\
\hline \multirow[t]{7}{*}{ Profitability ratios } & Return on Equity (ROE) & (Profit before tax / Shareholders funds) $* 100$ \\
\hline & Return on capital employed (ROCE) & (Profit before tax + Interest paid) $/$ (Shareholders funds + Non-current liabilities \\
\hline & Return on Total Assets (ROA) & 100 (Profit before tax / Total assets) $* 100$ \\
\hline & Profit Margin & (Profit before tax / Operating revenue) $* 100$ \\
\hline & Ebitda Margin & $($ EBITDA / Operating revenue) $* 100$ \\
\hline & Ebit Margin & $($ EBIT / Operating revenue $) * 100$ \\
\hline & Cash flow margin & $($ Cash flow / Operating revenue) $* 100$ \\
\hline \multirow[t]{4}{*}{ Operational ratios } & Net assets turnover & Operating revenue / (Shareholders funds + Non-current liabilities) \\
\hline & Interest cover & Operating profit / Interest paid \\
\hline & Stock turnover & Operating revenue / Stocks \\
\hline & Credit period & (Creditors / Operating revenue) $* 360$ \\
\hline \multirow[t]{3}{*}{ Structure ratios } & Current ratio & Current assets / Current liabilities \\
\hline & Liquidity ratio & (Current assets - Stocks) / Current liabilities \\
\hline & Solvency ratio & (Shareholders funds / Total assets) $* 100$ \\
\hline \multirow[t]{2}{*}{ Per employee ratios } & Profit per employee & Profit before tax / Employees \\
\hline & Operating revenue per employee & Operating revenue / Employees \\
\hline
\end{tabular}

\subsection{Methodology}

The methodology of this study involves the construction and estimation of an index, which ranks firms based on their relative position, using financial ratios as inputs. Based on the rank transformation, we propose to estimate a bankruptcy index, that takes into account the relative position of units in the ordered sample with respect to all financial ratios considered. In more detail, the proposed approach consists of a few steps. Initially, after computing the percentiles of financial ratios, the firms are classified by looking at the variables' ranks compared with the percentiles. A failure index is then computed, and since the aim is to estimate the probability of default, the logistic regression is applied to take into account the effect of the index on the likelihood of failure. Thanks to the regression estimates, some accuracy measures are computed in order to test and validate the procedure.

The logistic regression is one of the most used methods in business failure studies for estimating the default probability. In particular, it is an extension of simple linear regression and is used to study and predict the relationship between some predictors (in our case, the financial ratios and/or the business failure index) and the dependent variable that is binary (in our case failure vs non-failure) (Harrell, 2001).

Actually, an aggregate index could be useful in order to determine the overall position of each firm, at the same time obtaining a ranking of the different entities in term of financial health (Cabaleiro et al., 2013; Liao \& Mehdian, 2016). Furthermore, using many indicators separately could be too costly and problematic to manage, while a composite indicator can easily summarise multi-dimensional issues, supporting decision-makers (Saisana \& Tarantola, 2002).

In more details, let $X=\left\{x_{i j}, i=1, \ldots, n ; j=1, \ldots, p\right\}$ be the data matrix that contains the firms' information on input variables, where $n$ is the number of sampled firms, and $p$ is the number of financial ratios.

In the first step the percentile matrix of covariates $P=\left\{p_{j k}, j=1, \ldots, p, k=1, \ldots, K\right\}$, where $K$ refers to the number of 
percentiles to compute, e.g. $K=4$ for quartiles and $K=10$ for deciles, is built.

In the second step, the companies are ranked according to their variables' values compared with the percentiles. For example, if $k=10$ (i.e. the deciles are calculated), firms take a value of 10 if they are the least distressed, and they take the value of 1 if they are the most distressed. Therefore, the ranking matrix given by $R=\left\{r_{i j}, i=1, \ldots, n\right.$; $j=1, \ldots, p\}$, where $r_{i j}=k$ if $p_{j, k} \leq x_{i j}<p j, k+1$, with $k=1, \ldots, K$, is obtained.

In the third step, the ranks are then summed up and scaled by a factor of $(K * p)$ to obtain an aggregate index $I_{i}$ for each subject:

$$
I_{\mathrm{i}}=\frac{\sum_{j=1}^{p} r_{\mathrm{ij}}}{K * P} \quad i=1, \ldots, n .
$$

The index is within a sample measure that ranks firms based on their financial position, and is calculated over time to discriminate between bankrupt firms and non-bankrupt firms. The estimated index ranges between 0 and 1. The higher the index for a given firm, the lower the financial distress and the probability of bankruptcy of that firm.

Since the financial ratios belong to four areas according to the aspects of firms' structure which they refer to (Table $1)$, the failure index for each group is also computed.

Let $p_{g}$ be the number of variables in group $g(g=1, \ldots, G)$ such that $\sum_{g=1}^{G} p_{\mathrm{g}}=p$.

Therefore, the index for the generic group $g$ is given by:

$$
I_{i}^{g}=\frac{\sum_{j=1}^{p_{\mathrm{g}}} r_{i j}^{g}}{K * p_{\mathrm{g}}} \quad i=1, \ldots, n .
$$

where $r_{i j}^{g}$ is the percentile of variable $j$ belonging to group $g$ for the $i$-th firm.

The global failure index is then given by

$$
I_{\mathrm{i}}=\frac{\sum_{g=1}^{G} I_{i \mathrm{j}}^{g}}{G}
$$

It can be shown that the two equations (1) and (3) give the same results since they are the linear transformations of the variables.

After computing the index, we estimate the default probability by a logistic regression where the regressors are the index of all groups, and we compute some accuracy measures, that will be discussed in Section 2.3.

\subsection{Evaluation of Model Performance}

To assess the validity of our proposed approach, we compute some measures, that are easy to interpret and provide an immediate magnitude of the capacity of model's prediction and forecasting. Based on the classification matrix (Table 2), we consider the True Positive rate (TPr), that is the proportion of non-failed firms classified correctly $(\mathrm{TP} /(\mathrm{TP}+\mathrm{FN}))$, the True Negative rate $(\mathrm{TNr})$, that is the proportion of failed businesses classified correctly $(\mathrm{TN} /(\mathrm{FP}+\mathrm{TN}))$, the Positive Predictive Value (PPV), that represents the percentage of correct classification of non-bankrupt companies $(T P /(T P+F P))$, the Negative Predictive Value (NPV) that represents the percentage of correct classification of bankrupt companies $(T N /(F N+T N))$. In addition to these metrics, we also evaluated the area under the ROC curve (AUC) (Engelmann et al., 2003; Fawcett, 2006).

Table 2. Classification matrix for evaluating the proposed approach

\begin{tabular}{ccccc}
\hline \multicolumn{4}{c}{ True Class } \\
& Non-Failed & Failed \\
\hline Predicted & Non-Failed & True Positives (TP) & False Positives (FP) & TP+FP \\
Class & Failed & False Negatives (FN) & True Negatives (TN) & FN+TN \\
\hline & & TP+FN & FP+TN & TP+FN+FP+TN \\
\hline
\end{tabular}

These measures are computed for validating the proposed approach and evaluating its prediction ability.

The data for building the index is chosen from any time period prior to a certain date, and validation data are selected from time periods only after that date. Because approach validation is performed with out-of-time samples, time dependence can be detected using different validation sub-samples. In particular, the sample is divided into two sets. The first one (in-time) is used for testing the procedure and building the index and consists of all firms that are active and bankrupted at year $t$; the second set (out-of-time) is used for evaluating the prediction goodness and consists of all firms that are active and bankrupted in year $t+1$. 
Table 3 shows the scheme of sampling used for validating the proposed approach and assessing its forecasting ability, where $X(t)$ and $X(t+1)$ are the in-time and out-of-time sets, respectively. The in-time samples are displayed in bright grey, while the out-of-time sets are colored in grey. Three prediction windows are considered: 1-year ahead, 2-years ahead, and 3-years ahead.

Since the number of non-bankrupt firms is much higher than that of bankrupted firms and this significant difference could lead to a seriously imbalanced classification problem and a degradation in the final prediction performance, for all in-time and out-of-time sets, we use the method of stratified random sampling with stratification on the default indicator (Altman, 1968; Platt \& Platt, 2002) to collect the same number of bankrupt and non-bankrupt cases. The firms within each group are selected at random.

Table 3. Time windows considered for evaluating the prediction performance

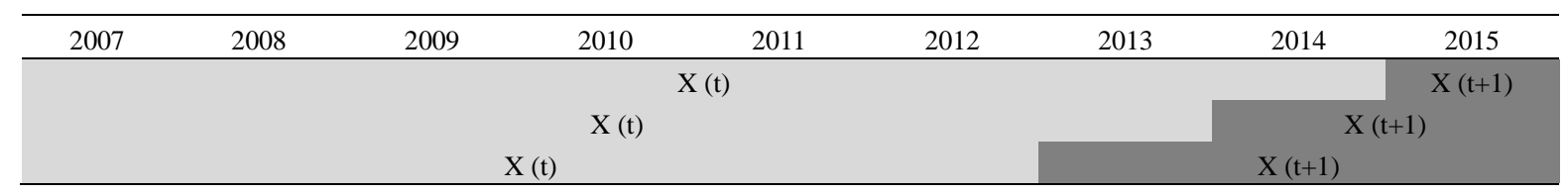

\section{Empirical Results}

\subsection{Results by Period for Validating the Approach}

In this section, we analyze the results achieved using the scheme shown in Table 3, to study the efficacy of the failure index and validate the approach, by evaluating the accuracy measures described in Section 2.3. Since we adopted a stratified random sampling in order to have the same number of bankrupt and non-bankrupt firms, for each window the samples are generated for 100 times, then the metrics are calculated for each replication, and their mean is then evaluated.

Tables 4 and 5 show the accuracy measures for the in-time and out-of-time sets. Looking at the true positive and true negative rates (TPr and $\mathrm{TNr}$ ), it can be noted how the suggested procedure is able to classify correctly both failed and unfailed firms. Moreover, looking at the values for the out-of-time sets, they increase when approaching at the year of bankruptcy, i.e. when the prediction goes from 3 years before bankruptcy to 1 year before the event of interest. This is also confirmed looking at the predictive values (PPV and NPV). Moreover, to test if the procedure is efficient for predicting the failure, we check if the AUC values are higher than 0.50, as the greater of the AUC, the better of the prediction model. Usually, a value of AUC between 0.5 and 0.7 means poor prediction model, a value ranging from 0.7 to 0.9 represents moderately better predictability, and a value between 0.9 and 1.0 presents the high predictability of the model. In our case, AUC is around 0.80 for the in-time sets and higher than 0.80 for the out-of-time samples, and therefore our procedure has a good predictive performance.

Table 4. Forecasting accuracy measures for in-time sets

\begin{tabular}{cccc}
\hline Measures & 1-year ahead & 2-year ahead & 3-year ahead \\
\hline TPr & 0.6813 & 0.6581 & 0.6434 \\
TNr & 0.7708 & 0.7883 & 0.7876 \\
Accuracy & 0.7291 & 0.7301 & 0.7238 \\
PPV & 0.7222 & 0.7154 & 0.7063 \\
NPV & 0.7344 & 0.7403 & 0.7356 \\
AUC & 0.7954 & 0.7914 & 0.7865 \\
\hline
\end{tabular}

Table 5. Forecasting accuracy measures for out-of-time sets

\begin{tabular}{cccc}
\hline Measures & 1-year ahead & 2-year ahead & 3-year ahead \\
\hline TPr & 0.7118 & 0.6581 & 0.6567 \\
TNr & 0.8889 & 0.7883 & 0.8651 \\
Accuracy & 0.8004 & 0.7301 & 0.7329 \\
PPV & 0.8632 & 0.7154 & 0.8942 \\
NPV & 0.7597 & 0.7403 & 0.5921 \\
AUC & 0.8692 & 0.7914 & 0.8412 \\
\hline
\end{tabular}




\subsection{Comparison of Results for the Two Procedures}

In this Section, we compare the forecasting ability of our proposed index and the procedure based on the original data. In order words, the default probability estimated by logistic regression where the independent variables are the index of all areas is compared with that computed when the regressors are the original variables. The evaluation is made by considering the same three-time windows considered in Section 3.1. Also in this case, since each sample is generated 100 times, the accuracy measures described in Section 2.3 are computed for each replication and the in-time and out-of-time samples, and their mean is then calculated.

Tables 6 and 7 show the results of comparison for the in-time and out-of-time sets, respectively. The results show that the proposed procedure has good performance. In fact, all measures of our proposed index are higher than those of the original data. This is true not only for the in-time sets used for building the index, but also for the out-of-time samples useful for evaluating the forecasting ability. In particular, our index seems to be better when the prediction is two or three years before the event of interest. Instead, our procedure does not make a significant improvement if compared with the procedure based on the original data, when the forecasting is one year ahead. Therefore, it seems that considering an aggregate index could be a good early warning instrument, adequate to give an alert before the occurrence of the event of interest.

Table 6. Comparison between the two procedures for the in-time sets

\begin{tabular}{ccccccc}
\hline \multirow{2}{*}{ Measures } & \multicolumn{2}{c}{ 1-year ahead } & \multicolumn{2}{c}{ 2-year ahead } & \multicolumn{2}{c}{ 3-year ahead } \\
\cline { 2 - 7 } & Index & Original & Index & Original & Index & Original \\
\hline TPr & 0.6813 & 0.6765 & 0.6581 & 0.9196 & 0.6434 & 0.9286 \\
TNr & 0.7708 & 0.8177 & 0.7883 & 0.2181 & 0.7876 & 0.1838 \\
Accuracy & 0.7291 & 0.7518 & 0.7301 & 0.5318 & 0.7238 & 0.5134 \\
PPV & 0.7222 & 0.7944 & 0.7154 & 0.5178 & 0.7063 & 0.4979 \\
NPV & 0.7344 & 0.7558 & 0.7403 & 0.8364 & 0.7356 & 0.8181 \\
AUC & 0.7954 & 0.8023 & 0.7914 & 0.5688 & 0.7865 & 0.5562 \\
\hline
\end{tabular}

Table 7. Comparison between the two procedures for the out-of-time sets

\begin{tabular}{ccccccc}
\hline \multirow{2}{*}{ Measures } & \multicolumn{2}{c}{ 1-year ahead } & \multicolumn{2}{c}{ 2-year ahead } & \multicolumn{2}{c}{ 3-year ahead } \\
\cline { 2 - 6 } & Index & Original & Index & Original & Index & Original \\
\hline TPr & 0.7118 & 0.7211 & 0.6581 & 0.9272 & 0.6567 & 0.9326 \\
TNr & 0.8889 & 0.8622 & 0.7883 & 0.3003 & 0.8651 & 0.2572 \\
Accuracy & 0.8004 & 0.7917 & 0.7301 & 0.7010 & 0.7329 & 0.6857 \\
PPV & 0.8632 & 0.8619 & 0.7154 & 0.7120 & 0.8942 & 0.7000 \\
NPV & 0.7597 & 0.7738 & 0.7403 & 0.8090 & 0.5921 & 0.7784 \\
AUC & 0.8692 & 0.8534 & 0.7914 & 0.6138 & 0.8412 & 0.5949 \\
\hline
\end{tabular}

\section{Discussion and Conclusion}

The global financial crisis of the last decade has increased the attention of scholars and policymakers on the importance of having warning signals to predict financial distress of firms in time. Several models have been proposed by scholars, building on the seminal papers of Beaver (1966) and Altman (1968).

The vast majority of these models can be labeled as parametric. However, as observed, parametric-based bankruptcy approaches suffer different limitations, such as: (i) the estimated discriminant coefficients are prevalently considered as constant; (ii) the potential multicollinearity problems between financial ratios are not taken into consideration while estimating the discriminant function, and the selection procedure adopted to reduce multicollinearity may lead to a misspecification of the model, because of the exclusion of potentially relevant ratios; (iii) the variables utilized are supposed to be normally distributed, and this is quite a restrictive assumption.

On the other hand, adopting non-parametric approaches, such as Data Envelopment Analysis (DEA) or artificial neural networks, may lead to different drawbacks; for example, DEA does not allow testing the statistical significance of coefficients, as it is not a stochastic approach.

Accordingly, scholars have suggested adopting a different approach, based on an aggregate index to predict corporate failure; for example, Liao and Mehdian (2016) have documented the higher predictive ability of their 
model compared to the classical multivariate discriminant analysis of the Altman (1968) Z-score model (they used the same five ratios used to build the Altman's model). However, Liao and Mehdian (2016) call for further research to assess the applicability of this approach.

This study has implemented this kind of approach, building a business failure index using rank transformation. Concretely, the aggregate index proposed in this paper has been computed by taking into account a larger number of ratios compared to those included in the model of Liao and Mehdian (2016), with the aim to capture several dimensions of the global financial condition of distressed firms (profitability ratios; operational ratios; structure ratios; per-employee ratios). In so doing, the model proposed in the current study, on the one hand, takes a global and holistic view; on the other hand, it facilitates the interpretation of potentially harmful and warning signals, by aggregating the multiple dimensions expressing the global performance of a firm in a single index.

Results emerging from this study demonstrate that the procedure based on the failure index shows a good capability of predicting the bankruptcy not only one year before the event, but also two and three years ahead. Moreover, to test the predictive ability of the model, a comparison with a classical logit regression has been carried out, using the same set of financial ratios adopted to build our aggregated index. Findings highlight the higher predictive capability of the proposed approach compared to the logit regression model, providing firms with a methodology to be used to capture early warning signals of distress.

From a theoretical perspective, this study contributes to the academic debate concerning the ability of forecasting models to predict financial distress, adding a new insight by assessing the applicability of aggregated indices. At the same time, it proposes an easy-to-apply model, through which stakeholders, such as financial institutions, investors, creditors and so forth, can monitor the evolving situation of the firm they are interested in. Actually, as underlined by scholars (Bellovary et al., 2007; Bisogno et al., 2018), implementing more and more complex models based on a high number of financial ratios does not lead to a higher predictive ability necessarily. The deserving attention issue is to provide managers, stakeholders and policymakers with straightforward approaches through which capturing trigger signals of incumbent distress. As underlined by Bisogno and De Luca (2014), a temporal approach should be adopted when examining the financial condition of a firm, taking into account the dynamic nature of the business failure, which evolves over time.

Therefore, our study can also provide implications for practitioners. Indeed, implementing warning and easy-to-understand signal procedures to detect financial risk and potential failure in time would support prompt interventions. Firms experiencing financial difficulties could have a second chance, implementing rescue remedies to solve troubling situations. Alternatively, if there are not concrete possibilities to restart the business, a bankruptcy proceeding can start promptly, avoiding losing value and reducing the so-called indirect costs of bankruptcy (Bisogno \& De Luca, 2012). Bearing in mind that the aggregate index implemented in this study is computed by transforming the variables into ranks, so that the firms are classified according to their position in the predictors' ranking, the model proposed in this article can provide a clear and easy-to-interpret tool to assess the financial condition of firms.

Following this line of reasoning, it is worthy of notice that the procedure proposed in this study is in line with a recent EU Directive proposal, based on the identification of early warning systems, in order to unveil potentially successful rescue remedies. This proposal aims to make timely interventions easier, at the same time harmonizing legislation between the member countries. Actually, many states have recently introduced several innovations in the last years (for example: Germany in 1999 and 2012; England, Enterprise Act 2002; Poland and Romania in 2003 and 2006; Spain in 2004 and 2013; Italy in 2005 and 2017; France in 2006 and 2014; Finland in 2007; Greece in 2007 and 2012). Although some differences still exist between bankruptcy legislation in the EU context, a common orientation towards corporate rescue can be observed, as an alternative to liquidation procedures, as underlined by Tollenaar (2017).

This study comes with a number of limitations that can be further addressed in subsequent studies. Firstly, a more complete set of financial ratios could be considered, in order to check which of them have effects on business distress and the failure index. Secondly, another important issue is to identify an optimal cut-off point of the index in order to classify the firms into the two groups, without estimating the logistic regression. Finally, since other studies consider that firms can exit the market for several reasons, such as bankruptcy, liquidation, merger \& acquisition, and so on (Schary, 1991; Bhattacharjee et al., 2009; Amendola et al., 2015), it might be worthwhile to consider all possible exits in order to build an index able to capture the differences between distress kinds. 


\section{References}

Altman, E. I. (1968). Financial ratios. Discriminant analysis and the prediction of corporate bankruptcy. Journal of Finance, 23(4), 589-609. https://doi.org/10.2307/2978933

Amendola, A., Restaino, M., \& Sensini, L. (2015). An analysis of the determinants of financial distress in Italy: A competing risks approach. International Review of Economics and Finance, 37, 33-41. https://doi.org/10.1016/j.iref.2014.10.012

Argenti, J. (1976). Corporate collapse: The causes and symptoms (pp. 5-6). New York: Wiley.

Beaver, W. H. (1966). Financial ratios as predictors of failure. Journal of Accounting Research, 4, 71-111. https://doi.org/10.2307/2490171

Bellovary, J., Giacomino, Don E., \& Akers, M. (2007). A Review of Bankruptcy Prediction Studies: 1930 to Present. Journal of Financial Education, 33, 1-42.

Bhattacharjee, A., Higson, C., Holly, S., \& Kattuman, P. (2009). Macroeconomic Instability and Business Exit: Determinants of Failures and Acquisitions of UK Firms. Economica, 76, 108-131. https://doi.org/10.1111/j.1468-0335.2007.00662.x

Bird, S. M., Cox, D., Farewell, V. T., Goldstein, H., Holt, T., \& Smith, P. C. (2005). Performance indicators: Good, bad, and ugly. Journal of the Royal Statistical Society: Series A, 168(1), 1-27. https://doi.org/10.1111/j.1467-985X.2004.00333.x

Bisogno, M., \& De Luca, R. (2012). Indirect costs of Bankruptcy: Evidence from Italian SMEs. Journal of Accounting and Finance, 2(1), 20-30.

Bisogno, M., \& De Luca, R. (2014). Bankruptcy Efficiency and Indirect Costs in Italian SMEs: A Temporal Approach. International Journal of Business Research and Development, 3(2), 12-27.

Bisogno, M., Restaino, M., \& Di Carlo, A. (2018). Forecasting and Preventing Bankruptcy: A Conceptual review. African Journal of Business Management, 12(9), 231-242. https://doi.org/10.5897/AJBM2018.8503

Cabaleiro, R., Buch, E. \& Vaamonde, A. (2013). Developing a Method to Assessing the Municipal Financial Health. The American Review of Public Administration, 43(6), 729-751. https://doi.org/10.1177/0275074012451523

Charitou, A., Neophytou, E., \& Charalambous, C. (2004). Predicting Corporate Failure: Empirical Evidence for the UK. European Accounting Review, 13(3), 465-497. https://doi.org/10.1080/0963818042000216811

Collins, J., \& Tuefli, T. (1992). Strategic risk: an ordinal approach. Management Science, 38, 1707-1731. https://doi.org/10.1287/mnsc.38.12.1707

Conover, W., \& Iman, R. (1980): The rank transformation as a method of discrimination with some examples. Communications in Statistics: Theory and Methods, 9(5), 465-487. https://doi.org/10.1080/03610928008827895

Crutzen, N., \& Van Caillie, D. (2007). The business failure process: Towards an integrative model of the literature. Ecole de Gestion de l'Universite de Liege Working Paper, 200710/03.

Deakin, E. B. (1972). A Discriminant analysis of Predictors of Business Failure. Journal of Accounting Research, 10(1), 167-179. https://doi.org/10.2307/2490225

Du Jardin, P., \& Severin, E. (2011). Predicting Corporate Bankruptcy Using a Self-Organizing Map: An Empirical Study to Improve the Forecasting Horizon of a Financial Failure Model. Decision Support Systems, 51(3), 701-711. https://doi.org/10.1016/j.dss.2011.04.001

Engelmann, B., Hayden, E., \& Tasche, D. (2003). Testing rating accuracy. Risk, 16, 82-86. https://doi.org/10.4236/jmf.2017.73034

Fawcett, T. (2006). An introduction to ROC analysis. Pattern Recognition Letters, 27, 861-874. https://doi.org/10.1016/j.patrec.2005.10.010

Frecka, T., \& Hopwood, W. (1983). The Effects of Outliers on the Cross-Sectional Distributional Properties of Financial Ratios. The Accounting Review, 58(1), 115-128.

Frydman, H., Altman, E. I., \& Kao, D. L. (1985). Introduction Recursive Partitioning for Financial Classification: The Case of Financial Distress. Journal of Finance, 40(1), 269-291. https://doi.org/10.1111/j.1540-6261.1985.tb04949.x 
Gepp, A., \& Kumar, K. (2008). The Role of Survival Analysis in Financial Distress Prediction. International Research Journal of Finance and Economics, 16, 13-34.

Gepp, A., Kumar, K., \& Bhattacharya, S. (2010). Business Failure Prediction Using Decision Trees. Journal of Forecasting, 29(6), 536-555. https://doi.org/10.1002/for.1153

Harrell, F. E. Jr. (2001). Regression Modeling Strategies. With Applications to Linear Models, Logistic and Ordinal Regression, and Survival Analysis. Springer-Verlag New York. https://doi.org/10.1007/978-3-319-19425-7

Iman, E., \& Conover, W. (1979). The use of the rank transform in regression. Technometrics, 21(4), 499-509. https://doi.org/10.2307/1268289

Jones, S., \& Hensher, D. A. (2004). Predicting firm financial distress: A mixed logit model. The Accountig Review, 14(4), 573-593. https://doi.org/10.2308/accr.2004.79.4.1011

Kane, G. D., \& Meade, N. L. (1998). Ratio Analysis Using Rank Transformation, Review of Quantitative Finance and Accounting, 10(1), 59-74. https://doi.org/10.1023/A:1008248130384

Kane, G. D., Richardson, F. M., \& Meade, N. L. (1998). Rank Transformation and the Prediction of Corporate Failure, Contemporary Accounting Research, 15(2), 145-166. https://doi.org/10.1111/j.1911-3846.1998.tb00553.x

Korol, T. (2013). Early warning models against bankruptcy risk for Central European and Latin American enterprises. Economic Modelling, 31, 22-30. https://doi.org/10.1016/j.econmod.2012.11.017

Lane, W., Looney, S., \& Wansley, J. (1986). An application of the Cox proportional hazards model to bank failure. Journal of Banking and Finance, 10, 511-531. https://doi.org/10.1016/S0378-4266(86)80003-6

Lee, C. (1985). Stochastic Properties of Cross-Sectional Financial Data. Journal of Accounting Research, 23(1), 213-227. https://doi.org/10.2307/2490915

Lennox, C. (1999). Identifying failing companies: A re-evaluation of the logit, probit and DA approaches. Journal of Economics and Business, 51(4), 347-364. https://doi.org/10.1016/S0148-6195(99)00009-0

Lertwachara, K., \& Boonchoo, P. (2006). An application of rank transformation: merger target predictions. $A U$ Journal of Management, 4(1), 33-42.

Lev, B., \& Sunder, S. (1979). Methodological Issues in Use of Financial Ratios. Journal of Accounting and Economics, 1(3), 187-210. https://doi.org/10.1016/0165-4101(79)90007-7

Liao, Q., \& Mehdian, S. (2016). Measuring financial distress and prediction corporate bankruptcy: An index approach. Review of Economic \& Business Studies, 9(1), 33-51. https://doi.org/10.1515/rebs-2016-0024

Luoma, M., \& Laitinen, E. (1991). Survival analysis as a tool for company failure prediction. Omega, 19(6), 673-678. https://doi.org/10.1016/0305-0483(91)90015-L

Ohlson, J. (1980). Financial ratios and the probabilistic prediction of bankruptcy. Journal of Accounting Research, 18(1), 109-131. https://doi.org/10.2307/2490395

Perez, M. (2006). Artificial neural networks and bankruptcy forecasting: A state of the art. Neural Computing and Application, 15(2), 154-163. https://doi.org/10.1007/s00521-005-0022-x

Perry, L., \& Cronan, T. (1986). A note on rank transformation discriminant analysis. Journal of Banking and Finance, 10, 605-610. https://doi.org/10.1016/S0378-4266(86)80008-5

Perry, L., Cronan, T., \& Henderson, G. Jr. (1985). Industry classification, ordinal data, and bond-rating decision models. Decision Sciences, 16, 14-24. https://doi.org/10.1111/j.1540-5915.1985.tb01472.x

Platt, H. D., \& Platt, M. B. (2002). Predicting Corporate Financial Distress: Reflections on Choice-Based Sample Bias. Journal of Economics and Finance, 26(2), 184-199. https://doi.org/10.1007/BF02755985

Saisana, M., \& Tarantola, S. (2002). State-of-the-Art Report on Current Methodologies and Practices for Composite Indicator Development. European Commission, Joint Research Centre.

Schary, M. A. (1991). The probability of exit. The RAND Journal of Economics, 22(3), 339-353. https://doi.org/10.2307/2601051

Shumway, T. (2001). Forecasting bankruptcy more accurately: A simple hazard model. Journal of Business, 74, 101-124. https://doi.org/10.1086/209665

So, J. C. (1987). Some Empirical Evidence on the Outliers and the Non-Normal Distribution of Financial Ratios. 
Journal of Business Finance \& Accounting, $\quad 14(4), \quad$ 483-496. https://doi.org/10.1111/j.1468-5957.1987.tb00108.x

So, J. C. (1994). The distribution of financial ratios - a note. Journal of Accounting, Auditing \& Finance, 9(2), 215-223. https://doi.org/10.1177/0148558X9400900205

Tollenaar, N. W. A. (2017). The European Commission's Proposal for a Directive on Preventive Restructuring Proceedings. Insolvency Intelligence, 30(5), 65-81.

Wilson, R. L., \& Sharda, R. (1994). Bankruptcy prediction using neural networks. Decision Support Systems, 11(5), 545-557. https://doi.org/10.1016/0167-9236(94)90024-8

Zmijewski, M. (1984). Methodological Issues Related to the Estimation of Financial Distress Prediction Models. Journal of Accounting Research, 22, 59-82. https://doi.org/10.2307/2490859

\section{Copyrights}

Copyright for this article is retained by the author(s), with first publication rights granted to the journal.

This is an open-access article distributed under the terms and conditions of the Creative Commons Attribution license (http://creativecommons.org/licenses/by/4.0/). 